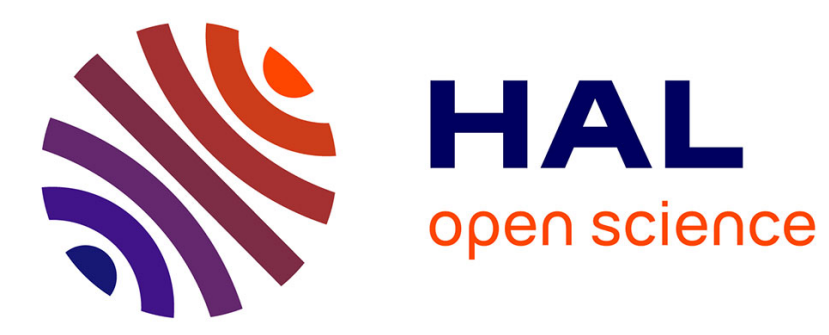

\title{
Requirements for IT Governance in Organizations Experiencing Decentralization
}

Jelena Zdravkovic, Irina Rychkova, Thomas Speckert

\section{To cite this version:}

Jelena Zdravkovic, Irina Rychkova, Thomas Speckert. Requirements for IT Governance in Organizations Experiencing Decentralization. Information Systems Engineering in Complex Environments, Jun 2014, Thessaloniki, Greece. pp.16, 10.1007/978-3-319-19270-3_17 . hal-01174651

\section{HAL Id: hal-01174651 \\ https://hal-paris1.archives-ouvertes.fr/hal-01174651}

Submitted on 9 Jul 2015

HAL is a multi-disciplinary open access archive for the deposit and dissemination of scientific research documents, whether they are published or not. The documents may come from teaching and research institutions in France or abroad, or from public or private research centers.
L'archive ouverte pluridisciplinaire HAL, est destinée au dépôt et à la diffusion de documents scientifiques de niveau recherche, publiés ou non, émanant des établissements d'enseignement et de recherche français ou étrangers, des laboratoires publics ou privés. 


\title{
Requirements for IT Governance in Organizations Experiencing Decentralization
}

\author{
Jelena Zdravkovic ${ }^{1}$, Irina Rychkova ${ }^{2}$, Thomas Speckert ${ }^{1}$ \\ ${ }^{1}$ Department of Computer and Systems Sciences, Stockholm University, Forum 100, \\ SE-16440, Kista, Sweden \\ jelenaz@dsv.su.se, thsp7525@dsv.su.se \\ ${ }^{2}$ Centre de Recherche en Informatique, Université Paris 1 Panthéon - Sorbonne, \\ 90 rue Tolbiac, 75013 Paris, France \\ irina.rychkova@univ-paris1.fr
}

\begin{abstract}
Decentralization of organizations and subsequent change of their management and operation styles require changes in organization's processes and heavily involve IT. Enterprise Architecture (EA) frameworks fit to primarily centralized organizational structures, and as such have shortcomings when used in decentralized organizations. We illustrate this idea on the example of one organization in the Higher Education sector that faces decentralization of its structure and has to adapt to it. Overcoming these challenges requires some new principles to be introduced and incorporated into the EA knowledge. In particular for IT governance, in this study we argue that peer-to-peer principles can offer more suitable governance over current EA frameworks as they are able to better align with decentralized components of an organizational structure.
\end{abstract}

Keywords: Enterprise Modeling, Enterprise Architecture, IT Governance.

\section{Introduction}

Enterprises have traditionally implemented formal, centralized forms of organizational structure [1], such as hierarchical or matrix structures. In these structures, communication patterns, roles and decision rights are strictly defined. This allows for management to have a high degree of control over the enterprise and therefore enforce compliance with standards, procedures and policies which results in a highly stable enterprise. However, this comes at the expense of agility; it is difficult for these organizations to quickly adapt to a changing environment. While centralized structures were appropriate for the business environments of the past, modern business environments demand a high level of agility [2].

The objective of EA methodologies created in early 1990s was to align IT capabilities with business needs via IT centralization. The main price to pay was the loss of flexibility and the inertia in decision making for IT. By that time, however, this was much less critical than to make the IT "disciplined" and to justify the investments in IT. Today, the flexibility in IT becomes more and more strategic. For modern 
organizations with transparent boundaries, loose business units and agile processes, it is impossible to centralize IT. On the other hand, it is still crucial to maintain "disciplined" approach in IT evolution using appropriate IT governance principles so that the organizational units not only remain independent but could also efficiently work together as a whole [3], [4].

Rapidly changing business conditions and structures have been identified as an important problem in EA [5, 6]. For these reasons, ensuring suitability of EA frameworks for decentralized organizational structures and IT governance which are highly dynamic, are increasingly relevant [7].

Our research has envisioned to addresses the problem of suitable EA and IT governance principles for decentralized organizations. The three concepts in focus interrelate - EA should be compliant with IT governance by including its principles or correlating with them, and in the way to reflect a given Organizational Structure.

Upon the described challenge, we have defined the following research question: $D o$, and if yes - how existing EA frameworks need to be extended in order to support IT Governance in decentralized organizations? Using a Design Science research method [8], [9,] including literature studies, interviews and document studies from an empirical case for data collection, and a qualitative approach for data analysis, we propose the artifacts summarizing shortcoming of current EA frameworks and formulating the requirements for IT governance for decentralized environments.

The paper is organized as follows: section 2 gives an overview of different organizational structures; in section 3 a brief description of the research method and proposed artifacts is given; in sections 4 , we describe the deficiencies of conventional EA frameworks for providing decentralization support; section 5 illustrates misalignment between EA principles, organizational structure, and IT governance principles on the example of one organization in Higher Education sector; based on that study, in section 6, we revisit the IT governance principles defined by Weill and Ross in [4] and provide explicit requirements for IT governance to support decentralization. Discussion, conclusions and directions of future work are presented in section 7.

\section{From Centralized to Decentralized Organizations}

The organizational structure defines the rules according to which allocation of responsibilities and resources, coordination and supervision, is made for an organization. In order to differentiate between centralized and decentralized organizations, we consider three organizational properties: geographical dispersion, coordination, and communication patterns [10-12].

On the continuum from centralized to decentralized structures, federated organizations have emerged combining characteristics of centralized organizations, such as centralized authority, planning and regulations, with for example local leadership, as well as competitive local objectives of including business units (decentralized aspects). 
Table 1. Organizational properties of centralized vs. decentralized organizations.

\begin{tabular}{|l|l|l|}
\hline Property & Centralized & Decentralized \\
\hline $\begin{array}{l}\text { Geographical } \\
\text { dispersion }\end{array}$ & Single location & $\begin{array}{l}\text { Geographically distributed with a } \\
\text { reliance on IS to work together }\end{array}$ \\
\hline $\begin{array}{l}\text { Coordination: } \\
\text { authority, } \\
\text { decision rights, } \\
\text { and regulations }\end{array}$ & $\begin{array}{l}\text { Vertical coordination: decision } \\
\text { rights are strictly defined and } \\
\text { act down from the top; strict } \\
\text { governance and control by the } \\
\text { upper management; rigid } \\
\text { structuring of accountability, } \\
\text { roles and responsibilities; } \\
\text { standardized methods and } \\
\text { procedures; homogeneous goals } \\
\text { set by high-level authorities }\end{array}$ & $\begin{array}{l}\text { Lateral coordination: authority and } \\
\text { decision making rights } \\
\text { are pushed down to the level } \\
\text { of business units, groups, or even } \\
\text { individuals; individuals can define } \\
\text { their own roles and responsibilities; } \\
\text { heterogeneous goals; individual } \\
\text { entities in the organization are } \\
\text { collaboratively working towards } \\
\text { some common or complementing } \\
\text { goals }\end{array}$ \\
\hline $\begin{array}{l}\text { Communication } \\
\text { patterns }\end{array}$ & $\begin{array}{l}\text { Communication patterns } \\
\text { follow the hierarchy; direct } \\
\text { interactions and communica- } \\
\text { tions are not practiced }\end{array}$ & $\begin{array}{l}\text { Informal communication lines; } \\
\text { flexible, constantly changing } \\
\text { communication lines; fluid, project- } \\
\text { oriented teams. }\end{array}$ \\
\hline
\end{tabular}

\section{$3 \quad$ Research Method}

Having the desire in our research to combine literature and empirical research to develop novel artifacts addressing the problem emphasized in Introduction, we have followed Design Science (DS) research method [8], also presented in [9] In a nutshell, the method is composed of five research activities with input-output relationships: explicate problem, outline artifact and define requirements, design and develop artifact, and evaluate artifact. These activities are commonly carried out in an iterative and incremental manner to enable changes and improvements of intermediate results, as well as of final research artifacts.

Adhering to space limitations of this paper, we will in our presentation mostly pay attention to the content of the artifacts and not to the DS process of achieving them; for details of the application of DS to our research, the reader can refer to [23].

The research has aimed to develop several artifacts. The first artifact presents conclusions obtained from the literature study on potential deficiencies of current EA to support decentralized organizations. The artifact has been in details elaborated in [13], while in section 4 we present its summary. The second artifact is the result of the empirical case study presented in section 5, proposing EA principles supportive for decentralized organizations [14]. The third artifact, making the use of the previous one, followed by an additional literature study, proposes a set of IT governance principles for a decentralized organizational context; it is presented in section 6 . 


\section{Deficiencies of EA Frameworks to Support Decentralization}

EA frameworks include artifacts to specify the current state of a company's architecture ("as-is"), the target architecture ("to-be"), identify how to best cross the gap between them (architectural roadmap), and to set up the standards and rules to follow during this transformation (EA principles). These elements are often addressed in literature as EA description; the process that an organization has to execute in order to obtain its EA description is called EA method. To assure that the organization will continuously follow the EA principles and achieve the designated goals (architecture "to-be") a third element has to be defined: EA engine. The presence of this reflects the fact that EA is not static: it makes the organization to change while changing itself over time.

In our research effort, the first task was to investigate how existing EA frameworks are supportive for decentralized organizations. The three key organizational properties from section 2 - geographical dispersion, coordination, and communication patterns were used to assess three wide-known frameworks - TOGAF [15], FEA [16], and Zachman Framework [17].

While the analysis [13] revealed some support for decentralization, the main conclusion drawn was that the EA frameworks of TOGAF, Zachman, and FEA are primarily supportive of centralized organizational structures, and therefore fail to address the demands of decentralized. A summarized view is provided in Table 2:

Table 2. Existing support of decentralization by EA frameworks.

\begin{tabular}{|l|l|l|}
\hline $\begin{array}{l}\text { EA } \\
\text { Component }\end{array}$ & $\begin{array}{l}\text { Existing support for centralized } \\
\text { organizations }\end{array}$ & $\begin{array}{l}\text { Existing support for } \\
\text { decentralized organizations }\end{array}$ \\
\hline EA Method & $\begin{array}{l}\text { Approval process is based on hierarchy; } \\
\text { architecture development is coordinated, } \\
\text { supervised and evaluated by well-defined } \\
\text { roles in a company; EA teams coordinate } \\
\text { architectural work and communicate results; } \\
\text { results are controlled and evaluated centrally. }\end{array}$ & $\begin{array}{l}\text { Federated architectures; } \\
\text { possibility to adapt ADM for } \\
\text { specific organizations; } \\
\text { architecture development } \\
\text { process involves multiple } \\
\text { stakeholders. }\end{array}$ \\
\hline EA Description & $\begin{array}{l}\text { Strategic level architectures; hierarchy } \\
\text { Of architecture principles; a common set of } \\
\text { reference models; hierarchical organization of } \\
\text { EA artifacts with explicitly defined roles and } \\
\text { domains. }\end{array}$ & $\begin{array}{l}\text { Architecture partitions; } \\
\text { architecture reference models; } \\
\text { segment architecture; the } \\
\text { concept of "shared vision". }\end{array}$ \\
\hline EA Engine & $\begin{array}{l}\text { Architecture board; formal governance } \\
\text { framework; common principles for entire } \\
\text { organization (global commitment is taken for } \\
\text { granted); centrally managed architecture } \\
\text { repository. }\end{array}$ & $\begin{array}{l}\text { Integration of various } \\
\text { segment) architectures is } \\
\text { assured by (centralized) } \\
\text { management and governance. }\end{array}$ \\
\hline
\end{tabular}

The important properties of a decentralized business environment that need to be supported by EA are horizontal coordination and lateral communication patterns. However, the three EA frameworks primarily support vertical coordination in their governance styles and top-down/bottom-up formal communication patterns. 


\section{Case Study}

We have analyzed a prominent university for higher education in Sweden. Our objective was to investigate the alignment between the organizational structure (including the organization of IT functions), and the EA and IT Governance rules in use. As common, the university includes a number of entities - faculties, faculty departments, and units. Nowadays, the entities are becoming more independent than before, due to several factors:

- Geographical dislocation. Some faculty departments have been moved out of the main university campus. An example is the Computer and Systems Sciences department located in Kista, the leading Swedish IT cluster. This proximity enables cooperation between IT companies and students through mentoring programs, internships, graduate work opportunities, guest lectures, etc.

- Decentralization of management. Decision rights are of the type "push-down" delegated by the principal to the faculty boards and deans, and some to the faculty departments and their units.

- Both formal and informal communication patterns. Formal hierarchical communication from the faculty to its departments, and informal direct communication between and within the departments are present. For example, the administrative tasks (such as registration for graduate courses, or postgraduate research, etc.) are primarily formal, whereas course curriculum can be established between departments cooperatively, using informal communication links.

Hence, the university is seen as having high decentralization tendencies. The study was to analyze the aspects of organization's EA and IT governance in order to assess the decentralization support provided, to reveal the deficiencies and to formulate the guidelines for an EA and IT governance in order to overcome these deficiencies.

This case is representative for the Higher Education sector: universities adopt more agile forms of organization including virtual research labs, scientific interest groups in research, joint master programs in education, and so on. As in the studied university, these examples involve geographical dislocation, decentralization of management, virtualization of communication, and use of informal communication patterns.

\subsection{Approach}

Four separate interviews were conducted in one of university's departments in order to get a holistic view of the way of work across the whole university. The roles of the interviewees were chosen to cover the major business activities of the institution management, research, education, and IT support: vice division lead, head of postgraduate studies, head of undergraduate studies, and head of IT support. The interviews were conducted face-to-face in a semi-structured manner, starting with a set of open-ended questions that promote the interviewees to elaborate on their views to organization's processes, decision making, coordination, etc.; for details of the interviews, the reader is referred to [23]. In addition, many official documents on the organizational structure are available, thus making a document study viable. The documents that formed this study are described in Table 3: 
Table 3. Documents used in the documentation study

\begin{tabular}{|l|l|}
\hline Document & Description \\
\hline Institution's homepage & $\begin{array}{l}\text { Contains descriptions of different topic areas of the institution as } \\
\text { well its organizational structure }\end{array}$ \\
\hline $\begin{array}{l}\text { Authority delegation } \\
\text { documents }\end{array}$ & $\begin{array}{l}\text { Publicly available documents specify authority and delegations of } \\
\text { said authority of the insinuation's organizational units }\end{array}$ \\
\hline Rule book & $\begin{array}{l}\text { The official rule book of the institution detailing the rules and } \\
\text { decisions that must be followed by the institution }\end{array}$ \\
\hline
\end{tabular}

\subsection{Results}

During our study, we found that despite an evident decentralization, EA principles used by the studied organization largely rely upon centralized coordination and vertical communication patterns. On the other hand, IT governance mechanisms currently used by this organization often adhere to decentralization and thus represent a mismatch with the existing EA. This problem is a serious constraint for successful evolution of organizational IT. For the purpose of this study, we illustrate our findings on the example of one established EA principle:

- Integrated IT systems across the university.

Owing to a federated organizational structure, and as in more details uncovered during the interviews, some decision rights are pushed down to the operational level, which for the IT-related organizational structure has resulted in highly decentralized governance:

Table 4. In-place IT governance mechanisms

\begin{tabular}{|l|l|l|}
\hline \multicolumn{1}{|c|}{ Name } & $\begin{array}{l}\text { Org. Property / } \\
\text { Centralization }\end{array}$ & \multicolumn{1}{|c|}{ Description } \\
\hline $\begin{array}{l}\text { Authority } \\
\text { structure }\end{array}$ & $\begin{array}{l}\text { Coordination / } \\
\text { Decentralized }\end{array}$ & $\begin{array}{l}\text { The department and the university have separate } \\
\text { IT and the departmental IT does not report to the } \\
\text { university. }\end{array}$ \\
\hline $\begin{array}{l}\text { IT adoption } \\
\text { (department) }\end{array}$ & $\begin{array}{l}\text { Coordination / } \\
\text { Decentralized }\end{array}$ & $\begin{array}{l}\text { Department IT does not dictate all IT used in the } \\
\text { department; research projects and centers; for } \\
\text { example, units can develop and use their own IT } \\
\text { systems should they desire. }\end{array}$ \\
\hline $\begin{array}{l}\text { Approval } \\
\text { (department) }\end{array}$ & $\begin{array}{l}\text { Coordination / } \\
\text { Mixed }\end{array}$ & $\begin{array}{l}\text { IT projects are run independently by groups, } \\
\text { though they sometimes need approval from the } \\
\text { department if they are expensive. }\end{array}$ \\
\hline IT collaboration & $\begin{array}{l}\text { Coordination / } \\
\text { Decentralized }\end{array}$ & $\begin{array}{l}\text { Any decision to cooperate with other departments } \\
\text { or with the university IT is made by the } \\
\text { departmental IT itself and is based on cooperation } \\
\text { resulting in mutual benefit. }\end{array}$ \\
\hline
\end{tabular}




\begin{tabular}{|l|l|l|}
\hline $\begin{array}{l}\text { Management } \\
\text { of "essential" central } \\
\text { IT systems }\end{array}$ & $\begin{array}{l}\text { Coordination / } \\
\text { Centralized }\end{array}$ & $\begin{array}{l}\text { "Essential" systems (e.g. administrative systems } \\
\text { such as HR) for the whole university are controlled } \\
\text { by the university board. The department is } \\
\text { required to pay for, and use these systems. }\end{array}$ \\
\hline $\begin{array}{l}\text { Management } \\
\text { of "non-essential" } \\
\text { central IT systems }\end{array}$ & $\begin{array}{l}\text { Coordination / } \\
\text { Mixed }\end{array}$ & $\begin{array}{l}\text { "Non-essential" systems (such as course portals } \\
\text { and schedules) are centrally budgeted, but } \\
\text { departments are not required to use them. }\end{array}$ \\
\hline $\begin{array}{l}\text { Use of IT systems } \\
\text { (department) }\end{array}$ & $\begin{array}{l}\text { Communication / } \\
\text { Decentralized }\end{array}$ & $\begin{array}{l}\text { Informal communication patterns are used, i.e. } \\
\text { when changes are performed on systems, they are } \\
\text { informally spread to those who use the systems. }\end{array}$ \\
\hline
\end{tabular}

The IT governance mechanisms described in the table are in a non-alignment with the established EA principle to integrate IT systems. As a consequence, IT governance initiatives typically fail, and decisions about IT become inefficient.

An example of immediate consequence of this is wasted financial resources: we consider a situation outlined in the interview with the head of IT of the department which concerned the acquisition of a software system with the objective of integrated facility management across departments (i.e. "integrated IT systems" principle). Following the principle, a software system has been bought for university-wide use; since the principle holds for the whole organization, the purchase was the decision of the university-board, i.e. the departments were not involved in the decision making process. In contrast, following the decentralized IT governance in-place for the use of "non-essential" software systems (Table 4), a subset of them consequently refused to shut down their local systems and switch to the global one. As a consequence, the principle of integration failed; the departments were able to protect their interests (local, decentralized systems tailored for their needs), but were still charged for the acquired system they never used. To improve the situation, the following problems need to be resolved:

- EA principles have to be aligned with the evolving organizational structure by acknowledging novel modes of coordination and communication;

- As a part of the EA engine, the IT governance has to be transparent and aligned with the established EA principles; in particular, it has to adequately support decentralization and to ensure efficient coordination and communication between organizational center and its sub-entities.

\subsection{Recommendations: Peer-to-Peer Principles}

Drawing parallels between the domains of peer-to-peer systems used to provide a mechanism and architecture for organizing peers in such a way so that they can cooperate to provide a useful service to a community of users [18] and decentralized organizations, we think that the peer-to-peer concept may be a source of the principles forming a basis for evolving current centralization-focused EA frameworks into ones that are supportive of decentralization.

Peer Production: we see organizations as being composed of peers (a peer could be individual, or an organizational unit), For example, TOGAF relies on an Architecture 
Board responsible for high-level decisions and governance. Instead of a central board responsible for making decisions, a model based on the principle of peer production [19] for creation and evaluation of EA artifacts could be used instead. This would better support decentralization as decision making would then be distributed amongst the peers that make the organization. In the university case, departments' members could produce strategy, or budget, using peer production (such as for use of information systems). Eventually, faculty or university boards could have control/advisory roles.

Peer trust management: TOGAF employs the idea of an approval process grounded on the presence of centralized authority. This is to ensure that the presented architectural material is in fact valid for the enterprise. According to peer trust management [20], whether some content proposed by a peer is of a sufficient quality to be included in the overall architecture, is determined by other peers. In the studied case, this principle could provide a formal mechanism for communication among peers when needed, hence avoid the situations when other peers are not informed about a new proposal (such as a change in IS use).

The suggested peer-to-peer principles will seek to maintain the departmental independence becoming prevalent at the university, while addressing the incompatible architecture components this results in. This would be accomplished through a cooperative classification of essential and non-essential software systems by the departments, for example by giving each department a vote. Systems classified as essential are required to be used or integrated by the departments, while departments have the option to choose if they want to utilize systems classified as non-essential. These changes would help at reconciling differences between the architecture principles emphasized in the case without actually changing it. Decision rights are still pushed down, and IT systems are still integrated throughout the organization; this change in IT governance at the university level addresses the conflict that can arise when a decision is made to use a decentralized system that the rest of the organization is integrating (as occurs in the current state).

\section{IT Governance Principles in Federated and Decentralized Organizations}

We have emphasized in the beginning that the notions of Organizational Structure, IT governance, and EA are interrelated: EA specifies architecture principles according to which both business and IT environment of the organization will evolve. Thus, it has to reflect the style of organizational structure. IT governance ensures that these architecture principles are respected by handling the everyday IT operations within the organization. In [21], the authors acknowledge that the organizational structure of a company (centralized, federated, decentralized) and its IT functions in particular affect the IT governance; the IT governance mechanisms hence need to be selected or designed taking this structure in to account. As a result of an extensive study of different organizations, in [4], Weill and Ross define 10 generic principles of IT Governance. Practice-inspired, these principles do not consider the organizational structure in-place. 
Upon an analysis, we concluded that some of the principles refer to structures and mechanisms adhering only to centralized organizations and require hence adaptation for federated and decentralized organizations. In particular, adaptation is needed for coordination mechanisms and communication patterns on which IT governance relies upon.

Our proposed adaptations are mainly based on the concepts defined by peer-to-peer domain, i.e. peer production and peer trust management (section 5): distributed content production, peer production of relevance and accreditation, peer review process and moderation, peer produced rating, peer trust management, decentralized decision making or group decision-making [19], [20]

The objective we pursue is twofold: first, we want to formulate requirements for IT governance in order to better support decentralization in organizations and, second, to provide relevant recommendations about tools to use in order to facilitate the coordination and communication (section 2).

\section{Principle 1: Actively design governance}

According to [4], management should actively design IT governance around enterprise's objectives and performance goals. Actively designing governance involves senior executives taking the lead and allocating resources, as well as for support to business processes.

Decentralized organizations: Due to management decentralization, senior executives do not play the leading role in the process coordination and resource allocation. Instead, coordination has to be grounded on the principles such as distributed content production and group decision-making. Traditional reporting/approval process used in centralized organizations can be replaced by peer review processes and peer produced rankings. Senior executives can play the role of moderators during the content creation. Lateral communication patterns (e.g. on-line and off-line informal discussions, content sharing) have to be employed replacing formal top-down/bottom-up communication patterns based on a hierarchy. Use of social software for communication and production of relevant content is an important requirement for IT governance in decentralized organizations: traditional meetings or workshops devoted to IT governance design can be highly inefficient as they assume centralized planning and require physical presence of assigned specialists in a given location, and at a given time.

In the studied case, IT governance principles supporting peer review of design are well recognized - one example is a by a unit proposed software system for thesis management; reviewed by the other units in iterations of system's development. Hence, a next step could be to extend good practices of coordination and communication patterns for reviewing to facilitate peer production as well. To summarize:

\begin{tabular}{|l|l|}
\hline RQ1 & $\begin{array}{l}\text { With a lack of centralized coordination, governance design process should } \\
\text { adhere to principles of distributed content creation and management. } \\
\text { Recommendation: group decision-making and peer reviewing can be seen } \\
\text { as an alternative to centralized approval process for coordination. }\end{array}$ \\
\hline RQ2 & $\begin{array}{l}\text { IT governance should encourage collaborative design, where each entity can } \\
\text { easily benefit from and contribute to a common organizational knowledge. } \\
\text { Recommendation: adoption and systematic use of IT and non-IT knowledge } \\
\text { management tools. }\end{array}$ \\
\hline
\end{tabular}


RQ3 Mechanisms supporting lateral communication patterns (informal social exchange, semi-formal discussions) have to be encouraged replacing vertical (hierarchy-based) communication patterns.

Recommendation: lateral communication can be facilitated using social software platforms.

Federated organizations: IT governance has to be designed at multiple levels: at the unit level, to support the autonomy of each unit, and at the corporate level, to maintain the consistency and foster cooperation between units. Successful coordination mechanisms should involve both elements of centralized coordination (e.g. centralized definition of objectives and performance goals, hierarchical assignment of tasks from the corporate level to the unit level), and decentralized elements based on the peer production principles (as defined for decentralized organizations). Both lateral communication patterns (i.e. from a unit to a unit) and top-down/bottom-up communication patterns (from a unit to the corporate level, and vice versa) have to be used. Efficiency in communication and content creation for both decentralized and federated organizations can be gained using commenting tools, on-line discussions, ranking and many other features provided by social software. Possibility to easily and instantaneously evaluate the content, to see evaluation of the others, and to get/receive feedbacks, guarantees a massive user involvement and fosters relevant content creation.

\begin{tabular}{|l|l|}
\hline RQ4 & $\begin{array}{l}\text { IT governance needs to support the synergy of units at the corporate level, } \\
\text { and units' autonomy at the unit level, by combining centralized coordination } \\
\text { with distributed (peer) production. See also RQ1. }\end{array}$ \\
\hline RQ5 & $\begin{array}{l}\text { Mechanisms combining lateral and vertical (top-down/bottom-up) } \\
\text { communication patterns have to be adopted (e.g. peer reviewing, } \\
\text { moderation) See also RQ3. }\end{array}$ \\
\hline
\end{tabular}

Principle 2: Know when to redesign

According to [4], rethinking the whole governance structure requires that individuals learn new roles and relationships. Learning takes time. Thus, governance redesign should be infrequent. The recommendation is that a change in governance is required with a change in desirable behavior.

Decentralized organizations: Compared to centralized organizations, where the governance structure is global and its change impacts the whole organization, entities in decentralized organizations can redesign the IT governance locally. Thus, on the smaller scale, the organizational learning takes less time and the changes can be made more frequently, allowing for more agility and flexibility. The whole organization can benefit from the experience of each of its business units by reusing their best practices. By sharing best practices and lessons learned, units contribute to the common pool of knowledge and foster the organizational learning.

In the studied case, a unit specialized for technology-enabled learning (TEL) is capable to propose redesign, such as use of new IT solutions and principles for "flexible learning" (spanning from off- to on-line) to improve organization's business. However, at the present time, neither a systematic coordination is installed, nor the TEL unit has real communication mechanism in place to share its knowledge for redesign. 


\begin{tabular}{|l|l|}
\hline RQ6 & $\begin{array}{l}\text { IT governance needs to encourage shorter cycles of organizational learning } \\
\text { for more flexibility and agility. }\end{array}$ \\
\hline RQ7 & $\begin{array}{l}\text { Systematic sharing of practice and lessons learned has to be an integrated } \\
\text { part of any governance redesign. } \\
\text { Recommendation: communities of practice, social networks, and } \\
\text { document libraries are examples of tools facilitating knowledge sharing. }\end{array}$ \\
\hline
\end{tabular}

Federated organizations: Organizational learning process consists of both short cycles when business units redesign their governance locally, and long cycles when the corporate IT governance is reorganized. The local redesigns have to be aligned with the corporate governance. IT governance evolution strongly depends on the capacity of units to share and reuse their local practices. Both lateral communication patterns (from unit to unit) and top-down/bottom-up communication patterns (from unit to the corporate level, and vice versa) have to be used.

RQ8 $\quad$ IT governance needs to support short cycles of organizational learning at the unit level and long cycles at the corporate level. See also RQ7.

\section{Principle 3: Involve senior managers}

In [4] it is argued that organizations with more effective IT governance have more of senior management involvement. For example, CIOs must be effectively involved in IT governance for success. Other senior managers must participate in the committees, the approval processes, and performance reviews.

Decentralized/Federated organizations: It is important to involve both senior management and local (unit) management in IT governance by forming committees, boards, and expert groups. Communities of practice $(\mathrm{COP})$ can be seen as an alternative for "assigned" groups of senior managers to steer the IT governance. A COP refers to a group of people who share a concern or a passion for something they do and has an objective to share and create common skills, knowledge, and expertise. These groups are formed on the volunteer basis and not by a hierarchical assignment; they also gain trust and reputation within the community of by professionals where they exist. Due to the lack of central authority, an approval process has to be grounded on the principles of group decision-making. In communication, an accent has to be made on knowledge sharing and cooperation over authority and hierarchy.

Due to a lack of appropriate coordination mechanisms, in the discussed case, there is a problem of non-involving units in management of the IT governance on the corporate level. The example in section 5.2 is an illustration of that.

\begin{tabular}{|l|l|}
\hline RQ9 & $\begin{array}{l}\text { Units have to be involved in IT governance management via boards and } \\
\text { expert groups. } \\
\text { Recommendation: COPs as an alternative to centrally assigned } \\
\text { boards/groups. }\end{array}$ \\
\hline RQ10 & $\begin{array}{l}\text { Combination of centralized approval process and distributed decision- } \\
\text { making has to be adopted for federated organizations. }\end{array}$ \\
\hline
\end{tabular}




\begin{tabular}{|l|l|}
\hline & $\begin{array}{l}\text { Recommendation: Performance review can be done using peer-reviewing } \\
\text { principles. }\end{array}$ \\
\hline
\end{tabular}

\section{Principle 4: Make choices}

According to [4], governance can and should highlight conflicting goals for debate. As the number of tradeoffs increases, governance becomes more complex. Top-performing enterprises handle goal conflicts with a few clear business principles."

Some of the most ineffective governance observed in [4] was the result of conflicting goals. The unmanageable number of goals typically arose from not making strategic business choices and had nothing to do with IT. It is observed that good managers trying diligently to meet all these goals became frustrated and ineffective.

Decentralized organizations: Having maximum autonomy, units can have different (event conflicting) goals. Peer ranking, peer trust management, peer reviewing and group decision-making are examples of the mechanisms to be adopted for coordinating conflict solving and decision-making. Social software platforms are indispensable instrument to support these mechanisms within the organization. Lateral communication patterns replace the traditional approval process.

In the case illustrated in section 5, this principle has not been yet implemented adequately: at the present time choices/goals are either determined centrally, or solely by the units, i.e. without communication to other units (i.e. goals are not shared).

\begin{tabular}{|l|l|}
\hline RQ11 & $\begin{array}{l}\text { IT governance needs to support local units' goals supporting group decision } \\
\text { making. } \\
\text { Recommendation: peer reviewing, peer ranking, peer trust management } \\
\text { are examples of mechanisms that can support "democratic choice" in } \\
\text { decentralized organizations. }\end{array}$ \\
\hline
\end{tabular}

Federated organizations: The goals and priorities are set up at different levels (corporate, and unit). Unit level goals have to be compliant with the corporate level goals. Between the units, the same coordination mechanisms and communication patterns as for decentralized organizations can be used to negotiate and to resolve the local conflicts.

\begin{tabular}{|l|ll}
\hline RQ12 & IT governance needs to support both centralized and decentralized
\end{tabular} mechanisms for decision making: "democratic choice" (see also RQ11) on the unit level, and compliance with few high level business principles.

\section{Principle 6: Provide the right incentives}

Following [4], a common problem encountered in studying IT governance was a misalignment of incentive and reward systems with the behaviors the IT governance arrangements were designed to encourage. If IT governance is designed to encourage business unit synergy, autonomy, or some combination, the incentives of the executives must also be aligned 
Decentralized organizations: Decentralized organizations support maximum of units' autonomy. In a number of situations, however, the benefits from the "whole" produced collectively, by units' synergy, exceed the benefits from components contributed by individual units. With the lack of central authority, these synergies can hardly be "encouraged" using regular market incentives. Their formation, however, can result from application of peer production principles and creation of production system based on collaboration among business units who cooperate without relying on either market pricing or managerial hierarchies to coordinate their common enterprise [22]. In this case, the incentives can include status, benefits to reputation, value of innovation to themselves [13]. Motivations can be cooperation are characterized by a combination of a will to create and to communicate with others [19].

Federated organizations: The challenge of federated organizations is to encourage units' synergy at the corporate level and units' autonomy - locally. To do so, an organization has to promote the culture of collaboration rather than competition between units. Collaborative environments pave the road to peer production systems; here the individual units are much more sensitive to non-market incentives and are willing to form synergies more than in the competitive environments based on "survival of the fittest" principles.

Contradictory incentives can represent a problem in Higher Education organizations like the one we studied: encouraging interdisciplinary Master programs on the university level (synergy) in exchange to reputation and recognition will not be efficient until each department is evaluated and financially rewarded based on its individual performance.

RQ13 $\quad$ IT governance needs to encourage cooperation instead of competition. Recommendation: use of nonmarket incentives (e.g. status, reputation)

\section{Principle 8: Design governance at multiple organizational levels}

The authors of [4] argue that in large multi-unit organizations, it is necessary to consider IT governance at several levels. The starting point is enterprise-wide IT governance driven by a small number of enterprise-wide strategies and goals. Enterprises with separate IT functions in divisions, business units, or geographies require a separate but connected layer of IT governance. Assembling the governance arrangements matrixes for the multiple levels in an enterprise makes explicit the connections and pressure points. This principle explicitly refers to IT governance with a complex organizational structure, and proposes multi-level governance.

Decentralized organizations Governance arrangements for decentralized organizations can vary from a set of autonomous "silos" to a single, distributed IT governance resulted from collaborative efforts of individual units. In both cases, only one governance level is explicitly defined.

In the discussed case, IT governance has been defined at multiple levels (department level, faculty level); its design, however, was not systematic as no coordination within level or between levels was provided. 
\begin{tabular}{|l|l|}
\hline RQ14 & Distributed IT governance can be encouraged in the organizations with
\end{tabular} cooperative culture; For highly competitive environments, governance "in silos" needs to be supported.

Federated organizations: For federated organizations that support both units' synergy (on the corporate level) and units' autonomy (locally, at the unit level), at least two IT governance levels have to be defined. The special attention has to be paid for adoption of collaborative software for facilitating lateral communication between units.

\begin{tabular}{|l|l|}
\hline RQ15 & IT governance needs to be defined at (at least) two levels: corporate and
\end{tabular} unit.

Principle 9: Provide transparency and education

According to [4], transparency and education often go together - the more education, the more transparency, and vice versa. The more transparency of the governance processes, the more confidence in the governance. Also, the less transparent the governance processes are, the less people follow them. Communicating and supporting IT governance is the single most important IT role of senior leaders.

Decentralized organizations: Communication and knowledge sharing supported by social software is extremely important for providing transparency and education in IT governance. Adopting technique and tools for distributed content production and collaborative content management, an organization can easily and naturally involve its employees into design of the IT governance process, thus guaranteeing its transparency for the users. Lateral communication patterns should be used - facilitated by senior experts, virtual or live, structured, semi-structured (e.g. webinars, workshops) or informal discussions (e.g. forums, chats, knowledge cafes) on the existing IT governance practice contribute to education and foster the organizational learning.

In the given case, this principle is enabled through the means of internal social software, however its broad use is typically ensured only in the situations when a higher level has provided the approval of a "knowledge" and has given recommendations for its use (.i.e. lateral communication is not in place).

\begin{tabular}{|l|l|}
\hline RQ16 & $\begin{array}{l}\text { IT governance needs to ensure employees involvement into the IT } \\
\text { governance design process. } \\
\text { Recommendation: distributed content production and management, social } \\
\text { software. }\end{array}$ \\
\hline RQ17 & $\begin{array}{l}\text { To foster the education and organizational learning, IT governance needs } \\
\text { to extensively use lateral communication patterns }\end{array}$ \\
\hline
\end{tabular}

Federated organizations: Techniques and tools for distributed content production and collaborative content management play equally important role in achieving transparency in the IT governance process as in decentralized organizations. The role of senior leaders is to setup learning objectives, to supervise the education process, and to evaluate its outcomes. 


\section{Discussion, Conclusion and Future Work}

In this study we have addressed the challenge of suitable EA and IT governance principles for decentralized organizations arguing that existing frameworks offer a limited support, and that new principles are needed in order to make them to fully support decentralized organizational structures.

While technology serves as a catalyst for organizational transformations, it is important to utilize right IT resources, and in a supportive manner. To accomplish this in decentralized organizations, adequate EA processes, principles and concepts need to be employed to both handle the IT resources and to foster business/IT co-evolution.

We have used an institution of Higher Education in Sweden as an illustrative case study. This case was chosen as an example of an organization that exhibits many decentralized properties (in particular with respect to IT governance). The focus was on analyzing the state of its EA in order to assess the decentralization support provided, in contrast with what is needed; and proposing features of an EA and in particular IT governance principles, that could provide the needed support. Our proposed recommendations are mainly based on the 2 principles defined by peer-to-peer domain - peer production and peer trust management. These principles were evaluated by a demonstration to the interviewees in the case; and argumentatively seen as applicable / valid to "university" contexts, which are shifting more and more to decentralization; however no validation on this issue was conducted for other organization types. Hence, the current work is based on a single case study that illustrated the argued limitations of current EA and non-alignment with IT governance in-place, and thus gave us a foundation for proposing new principles for EA and IT governance; however the case study did not validate the proposed principles.

To generalize and stream-forward our foundations from the case, we have in section 6 revisited the IT governance principles defined by Weill and Ross in [4], and following them defined a set of requirements for IT governance in supporting the specifics of federated and decentralized organizations. We believe that they may be of interest to three groups: the case organization, researchers in the field of EA, and, potentially, other organizations with decentralized structures interested in implementing some form of EA. For the case organization, the proposed mechanism of peer production, reviewing and trust, also embedded into requirements for adequate IT governance, might be important as their application could offer some improvements to their governance structure. For researchers, this study work might be of interest as it highlights some potential issues with traditional EA knowledge, while giving guidelines on how they could be solved. This work may be of interest to organizations that have adopted, or are interested in adopting a decentralized structure and are looking for the insights into how governance can be successfully done in this environment.

For the future work, our short term objective is to evaluate our conclusions in the given case context, and then to extend our study and in other organizations. In long terms, we envisage to in more details analyze mechanisms for coordination (decision making) as well as communication patterns, in centralized, decentralized and mixed (federated) organizations, and to see how they can be transformed into IT governancetype patterns, and how to merge them into exiting EA methodologies. 


\section{References}

1. Pearlson, K. E. and Saunders, C. S. Strategic Management of Information Systems, 4th ed. John Wiley \& Sons, (2009)

2. Fulk, J. and DeSanctis, G. Electronic communication and changing organizational forms. Organization science, vol. 6, no. 4, pp. 337-349 (1995)

3. Rockart, J., Earl, M. and Ross, J. Eight imperatives for the new IT organization. Sloan management review, pp. 43-56, (1996)

4. Weill, P. and Ross, J. W. IT Governance: How Top Performers Manage IT Decision Rights for Superior Results. Harvard Business School Press, Boston (2004)

5. Lucke, C., Krell, S. and Lechner, U. Critical Issues in Enterprise Architecting - a Literature Review. in AMCIS 2010 Proceedings. (2010) At http://aisel.aisnet.org/amcis2010/305

6. Bente, S, Bombosch, U. and Langade, S. Collaborative Enterprise Architecture: Enriching EA with Lean, Agile, and Enterprise 2.0 Practices. Morgan Kaufmann, (2012)

7. Ross, J. W., Weill, P. and Robertson, D. Enterprise Architecture As Strategy: Creating a Foundation for Business Execution. Harvard Business Review Press (2006)

8. Hevner, A. R., March, S. T., Park, J. and Ram, S. Design science in information systems research. MIS Quarterly, vol. 28, no. 1, pp. 75-105 (2004)

9. P. Johannesson and E. Perjons, A Design Science Primer, 1st ed. CreateSpace, 2012. Available at: http://designscienceprimer.wordpress.com

10. F. Luthans, Organizational behavior. McGraw-Hill/Irwin (2006)

11. Ahuja, M. K. and Carley, K.M. Network structure in virtual organizations Journal of Computer-Mediated Communication, vol. 3, no. 4 (1998)

12. L. G. Bolman and T. E. Deal, Reframing Organizations, 4th ed. San Francisco, California: John Wiley \& Sons (2008)

13. Speckert T., Rychkova I., Zdravkovic J., and Nurcan, S. On the Changing Role of Enterprise Architecture in Decentralized Environments: State of the Art. To appear in proceedings of $8^{\text {th }}$ International Workshop on Trends in Enterprise Architecture Research (TEAR). 9-13 September, Vancouver, BC, Canada (2013)

14. Zdravkovic, J., Rychkova, I. and Speckert, T. IT Governance in Organizations Facing Decentralization - Case Study in Higher Education. Proceedings of the 26th CAiSE'2014 Forum. Available at: http://ceur-ws.org/Vol-1164/

15. The Open Group, TOGAF Version 9.1. The Open Group, (2011)

16. Federal Enterprise Architecture Program Management. FEA Practice Guidance. (2007)

17. Zachman, J. A. John Zachman's Concise Definition of The Zachman Framework. (2008) At http://www.zachman.com/about-the-zachman-framework

18. Saroiu, S., Gummadi, P. K. and Gribble, S. D. Measurement study of peer-to-peer file sharing systems. In El. Imaging, International Society for Optics and Photonics, pp. 156-170 (2001)

19. Benkler, Y. The wealth of networks: How social production transforms markets and freedom. Yale University Press (2006)

20. Aberer, K. and Despotovic, Z. Managing Trust in a Peer-2-Peer Information System. In Proceedings of the $10^{\text {th }}$ International Conference on Information and Knowledge Management ACM, pp. 310-317 (2001)

21. De Haes, S. and Grembergen, V. W. IT Governance and its Mechanisms. Information Systems Control Journal 1, 27-33 (2004)

22. Benkler, Y. Coase's penguin, or Linux and the nature of the firm. Yale Law Journal, 112, 369-446 (2002)

23. Speckert, T. Enterprise Architecture for Decentralized Environments". Master thesis, https://daisy.dsv.su.se/fil/visa?id=104520 (2013) 